\title{
Xylitol concentrations in artificial saliva after application of different xylitol dental varnishes
}

\author{
Agnes de Fátima Faustino PEREIRA ${ }^{1}$, Thiago Cruvinel da SILVA ${ }^{2}$, Thelma Lopes da SILVA ${ }^{3}$, Magali de Lourdes \\ CALDANA ${ }^{4}$, José Roberto Magalhães BASTOS ${ }^{5}$, Marília Afonso Rabelo BUZALAF ${ }^{6}$ \\ 1- MSc, PhD, Assistant Professor, School of Dentistry, University of Cuiabá, Cuiabá, MT, Brazil. \\ 2- DDS, MSc, PhD, Assistant Professor, School of Dentistry, University of Cuiabá, Cuiabá, MT, Brazil. \\ 3- BSc, MSc, Department of Biological Sciences, Bauru School of Dentistry, University of São Paulo, Bauru, SP, Brazil. \\ 4- MSc, PhD, Assistant Professor, Speech-Language Pathologist, Department of Speech Pathology and Audiology, Bauru School of Dentistry, University of \\ São Paulo, Bauru, SP, Brazil. \\ 5- DDS, MSc, PhD, Full Professor, Department of Pediatric Dentistry, Orthodontics and Community Health, Bauru School of Dentistry, University of São Paulo, \\ Bauru, SP, Brazil. \\ 6- DDS, MSc, PhD, Full Professor, Department of Biological Sciences, Bauru School of Dentistry, University of São Paulo, Bauru, SP, Brazil
}

Corresponding address: Profa. Dra. Marília Afonso Rabelo Buzalaf, PhD - Faculdade de Odontologia de Bauru - USP - Departamento de Ciências Biológicas - Alameda Dr. Octávio Pinheiro Brisolla, 9-75 - Bauru - SP - 17012-901 - Brazil - e-mail: mbuzalaf@fob.usp.br

Received: January 21, 2010 - December 15, 2009 - Modification: February 25, 2010 - Accepted: March 17,2010

\section{ABSTRACT}

bjective: The present study analyzed xylitol concentrations in artificial saliva over time
after application of varnishes containing $10 \%$ and $20 \%$ xylitol. Material and Methods:
Fifteen bovine enamel specimens $(8 \times 4 \mathrm{~mm})$ were randomly allocated to 3 groups $(\mathrm{n}=5 /$
group), according to the type of varnish used: $10 \%$ xylitol, $20 \%$ xylitol and no xylitol
(control). After varnish application $(4 \mathrm{mg})$, specimens were immersed in vials containing
$500 \mu \mathrm{L}$ of artificial saliva. Saliva samples were collected in different times $(1,8,12,16$,
24,48 and $72 \mathrm{~h}$ ) and xylitol concentrations were analyzed. Data were assessed by two-
way repeated-measures ANOVA ( $<0.05)$. Results: Colorimetric analysis was not able to
detect xylitol in saliva samples of the control group. Salivary xylitol concentrations were
significantly higher up to 8 h after application of the $20 \%$ xylitol varnish. Thereafter, the
$10 \%$ xylitol varnish released larger amounts of that polyol in artificial saliva. Conclusions:
Despite the results in short-term, sustained xylitol releases could be obtained when the
$10 \%$ xylitol varnish was used. These varnishes seem to be viable alternatives to increase
salivary xylitol levels, and therefore, should be clinically tested to confirm their effectiveness.

Keywords: Xylitol. Artificial saliva. Dental caries.

\section{INTRODUCTION}

The influence of xylitol on the control of risk factors and prevention of dental caries has already been assessed in several studies ${ }^{1,5-12,16-18,21-24,26}$. The outcomes of this strategy seem to depend on the detection of minimal salivary levels of that polyol along time ${ }^{28}$. However, the rapid clearance of xylitol from the oral cavity can explain the short-term increase of salivary xylitol concentrations after the use of vehicles such as candies, chewing gums, dentifrices and solutions ${ }^{15,16,18,24,25}$.

High frequencies of intake of xylitol have been employed in most of the studies so that its anticariogenic effects could be observed in clinical trials ${ }^{1,5-12,14,16-18}$. However, these protocols could cause discomfort to the patient and strongly rely on compliance ${ }^{25}$, which turns difficult the use of xylitol in daily clinical practice. Thus, the need of vehicles that could allow sustained xylitol release along time has been recognized ${ }^{25,28}$.

Fluoride $^{22}$, chlorhexidine ${ }^{3}$, copper $^{29}$ and iron ${ }^{13}$ have been shown to be successfully delivered when incorporated into dental varnishes because their adherence to tooth surface leads to longer maintenance of these different agents in the oral cavity. However, to our knowledge, no attempt was made to include xylitol into a varnish formulation so far. Hence, the present in vitro study aimed at analyzing the xylitol concentrations in artificial saliva along time after application of varnishes containing $10 \%$ and $20 \%$ xylitol. 


\section{MATERIAL AND METHODS}

\section{Preparation of bovine enamel specimens}

Enamel specimens were obtained from lower bovine incisors. After visual inspection, stained and/or cracked teeth were excluded. Besides, soft tissues were removed from the coronal and root surfaces with the aid of a periodontal curette (Duflex ${ }^{\circledR}$, SSWhite, Rio de Janeiro, RJ, Brazil). Fifteen enamel specimens $(8 \times 4 \mathrm{~mm})$ were obtained after two double sections of the widest portion of the dental crowns, as described by Magalhães, et al.19 (2008). Subsequently, the specimens were numbered and randomly allocated to 3 different groups ( $n=5 /$ group), according to the type of varnish that would be applied: (1) $10 \%$ xylitol (FGM/Dentscare, Joinville, SC, Brazil); (2) $20 \%$ xylitol (FGM/Dentscare) and (3) no xylitol (control; FGM/Dentscare).

\section{Varnish application}

Three different varnishes (control, containing $10 \%$ and $20 \%$ xylitol) were especially manufactured by FGM/Dentscare for the present research. Xylitol concentrations were determined by the maximum incorporation of that polyol into the varnish that would not lead to precipitation. Varnishes used contain colophonium, synthetic resin, thickening polymer, essence and ethanol in their composition (informed by manufacturer). Xylitol was supplied by Danisco (Xylitab ${ }^{\circledR}$ 300, Danisco Brasil Ltda, Cotia, SP, Brazil). Xylitol and control varnishes did not contain fluoride or any other antimicrobial agent.

Enamel specimens were weighed before and after varnish application to standardize the amount used. After a pilot study, $4 \mathrm{mg}$ of the respective varnish were applied on a dry bovine enamel specimen with a microbrush. It was the maximum amount that could be applied considering the area of the specimens. After $10 \mathrm{~min}$, each specimen was inserted into a microcentrifuge tube containing 500 $\mu \mathrm{L}$ of artificial saliva $\left(1.5 \mathrm{mmol} / \mathrm{L} \mathrm{Ca}\left(\mathrm{NO}_{3}\right)_{2} \mathrm{H}_{2} \mathrm{O} ; 0.9\right.$ $\mathrm{mmol} / \mathrm{L} \mathrm{Na}_{2} \mathrm{HPO}_{4} .2 \mathrm{H}_{2} \mathrm{O} ; 150 \mathrm{mmol} / \mathrm{L} \mathrm{KCl} ; 0.1 \mathrm{~mol} / \mathrm{L}$ $\mathrm{H}_{2} \mathrm{NC}\left(\mathrm{CH}_{2} \mathrm{OH}\right)_{3}$ (TRIS); $\left.0.05 \mu \mathrm{g} / \mathrm{mL} \mathrm{NaF}, \mathrm{pH} 7.0\right)^{30}$.

\section{Times of immersion in artificial saliva}

Sample size and times of immersion of the specimens in artificial saliva were chosen based on results of a pilot study (data not shown). After 1,8 , $12,16,24,48$ and $72 \mathrm{~h}$ from the first immersion, each specimen was removed, washed with deionized water and placed into another microcentrifuge tube containing $500 \mu \mathrm{L}$ of fresh artificial saliva at room temperature. Saliva samples were frozen until colorimetric analysis.

\section{Analysis of xylitol in artificial saliva}

The analysis of xylitol concentrations in artificial saliva was performed by a colorimetric method, using a spectrophotometer (Ultrospec 2000 UV/ Visible Spectrophotometer, Pharmacia Biotech, Cambridge, USA) and an enzymatic kit D-Sorbitol/ Xylitol (Boehringer Mannheim, R-Biopharm, Darmstadt, Germany). A standard curve was obtained in triplicate using five different amounts of xylitol $(0.5,2.0,5.0,8.0$ and $10 \mu \mathrm{g})$. The absorbance was read at $492 \mathrm{~nm}$. A mathematical equation determined by the manufacturer of the enzymatic kit was used to convert the values of absorbance into xylitol concentration ( $\mathrm{mg} / \mathrm{L}$ ). All samples were analyzed in duplicate and the mean repeatability of the readings was $98.6 \%$.

\section{Statistical analysis}

Graph Pad InStat version 3.0 for Windows and Graph Pad Prism version 4.0 for Windows (Graph Pad Software Inc., San Diego, USA) were used. Since data presented a normal distribution (Kolmogorov-Smirnov test) and homogeneity (Bartlett test), they were analyzed by two-way repeated-measures ANOVA followed by Bonferroni's post hoc test for individual comparisons.

\section{RESULTS}

Regardless of the time of immersion, xylitol could not be detected in artificial saliva samples of the control group. Consequently, data obtained only after application of xylitol-containing varnishes are presented.

Mean xylitol concentrations in artificial saliva ranged between $63.4 \pm 2.7 \mathrm{mg} / \mathrm{L}(1 \mathrm{~h})$ and $32.7 \pm 0.9$ $\mathrm{mg} / \mathrm{L}(72 \mathrm{~h}$ ) after application of $10 \%$ xylitol varnish and between $169.0 \pm 1.5 \mathrm{mg} / \mathrm{L}(1 \mathrm{~h})$ and $12.7 \pm 0.4$ $\mathrm{mg} / \mathrm{L}$ ( $72 \mathrm{~h}$ ) after application of $20 \%$ xylitol varnish (Figure 1). Significant differences were detected for the variables varnishes $(F=33, p=0.0004)$ and times of immersion in saliva $(F=2,466, p<0.0001)$, as well as a significant interaction between these criteria $(F=1,486, p<0.0001)$.

In overview, a reduction of xylitol concentration was observed along time for both varnishes, except for $48 \mathrm{~h}$ after immersion in artificial saliva. Nevertheless, a greater reduction could be noticed after application of $20 \%$ xylitol varnish than after application of $10 \%$ xylitol varnish (Figure 1 ). In the short-term (up to $8 \mathrm{~h}$ ), xylitol concentrations in saliva were significantly higher after application of $20 \%$ xylitol varnish in comparison to its counterpart $(p<0.001)$. This relationship was inverted after 12 $\mathrm{h}$ from application of the xylitol varnish during the remaining time $(p<0.001)$. 


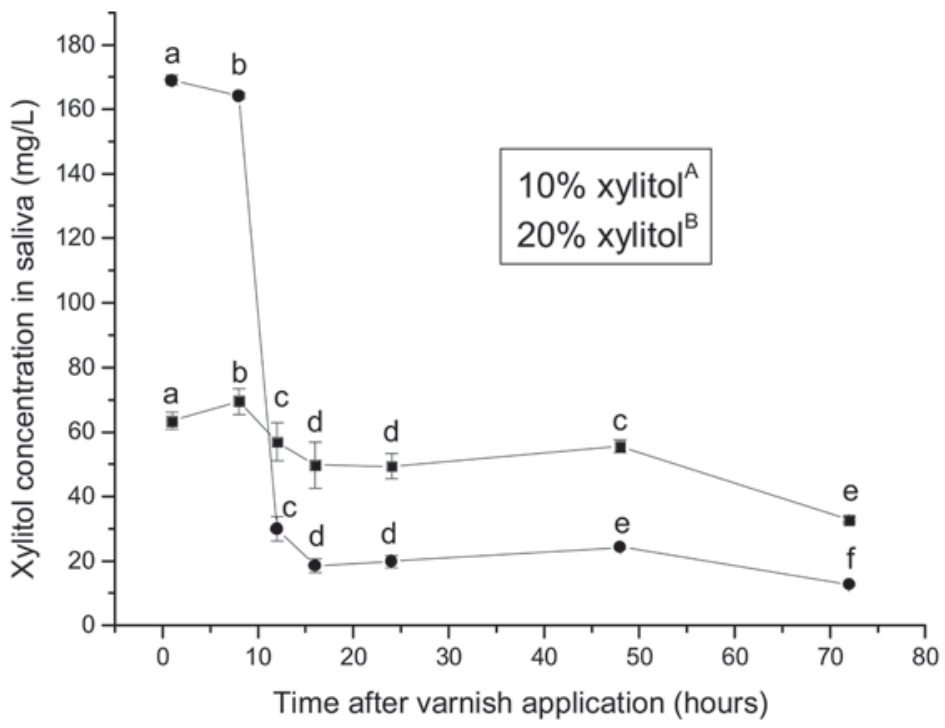

Figure 1- Mean accumulated xylitol concentrations (mg/L) in artificial saliva over time after application of $10 \%$ and $20 \%$ xylitol varnishes. Bars indicate SD $(n=5)$. Distinct uppercase letters indicate significant differences between the varnishes. Distinct lowercase letters indicate significant differences among time points for each varnish (two-way RM ANOVA, p<0.05)

\section{DISCUSSION}

When the use of xylitol is aimed to prevent dental caries, important parameters such as frequency of administration, dose-response, and minimal salivary concentration must be regarded. However, such clinical conditions have not been established yet ${ }^{12,14,20,23}$. The amount of $5 \mathrm{~g}$ of xylitol, divided in at least 3 times per day, is supported for a considerable number of studies as the minimum clinical effective dose to achieve prevention of dental caries. On the other hand, some studies were successful in using lower doses and/or frequencies of that polyol ${ }^{26}$. It has been recently reported that $0.01 \%$ xylitol was able to inhibit in vitro growth of mutans streptococci ${ }^{28}$, but the extent to which this information can be transferred to the clinical situation demands further investigation.

Randomized clinical trials normally use daily xylitol amounts that vary between 2 and $15 \mathrm{~g}$, divided in 3 to 5 times per day, delivered mainly by chewing gums 6,9-12,20. However, this protocol can be considered cumbersome ${ }^{25}$. It is desirable to develop new vehicles able to promote a sustained release of xylitol in saliva along time. Hence, xylitol-containing varnishes were formulated and tested in the present study. Dental varnishes can be used in lower frequencies and mastication is not required for their effectiveness which improves patient's compliance. Additionally, the varnishes were manufactured with a fruit flavor to make them more suitable for babies and young children, compared to chewing gums or solutions ${ }^{4}$.

It also has been recognized that the frequency of use of xylitol seems to be more important in the prevention of dental caries than the amount of that polyol 24,27,28. Xylitol is rapidly removed from the oral cavity after application of the vehicles commonly available. Lif Holgerson, et al. ${ }^{15}$ (2006) observed that salivary xylitol levels can be significantly increased up to 16 min by mastication of chewing gums containing $1.32 \mathrm{~g}$ of xylitol or by mouth rinsing with $10 \%$ xylitol solution. Tablets, candies and dentifrices were able to enhance salivary levels of that polyol up to $8 \mathrm{~min}$ after be used. Accordingly, the varnishes might have a great advantage over the other vehicles.

This pioneer study evaluated the potential of a newly developed varnish to release xylitol in a medium that resembles the composition of natural saliva along time. Therefore, a positive control group with xylitol delivered via another vehicle, such as chewing gum, was not included. Bovine enamel specimens were immersed in artificial saliva and they were kept under gentle agitation to simulate the movements that occur in the mouth. Conditions as salivary flow and temperature of the oral cavity were not simulated.

In this study, the amount of varnish (4 mg) applied on each specimen might contain 40 and $80 \mathrm{mg}$ of xylitol in $10 \%$ and $20 \%$ varnishes, respectively, which is very low when compared to that is recommended for prevention of dental caries. However, the volume of varnish usually applied in the whole mouth is around $0.2 \mathrm{~mL}$ ( $200 \mathrm{mg}$ ), nearly 50 times larger than that used in the present research. Consequently, it could be clinically expected that around 2 and $4 \mathrm{~g}$ of xylitol would be found in the oral cavity after applying respectively $10 \%$ and $20 \%$ xylitol varnishes. Higher concentrations of $20 \%$ xylitol could not be incorporated into the varnishes without precipitation. 
Regarding safety considerations, high doses of xylitol ingested by adults and children can cause adverse gastrointestinal effects ${ }^{2}$. Adults can tolerate the intake of up to $200 \mathrm{~g}$ of xylitol per day, while children can ingest up to $45 \mathrm{~g}$ per day. Then, even if the xylitol varnishes would be applied on all dental surfaces, the amount of xylitol that could be ingested is completely safe.

We believe that more homogeneous varnishes might provide more sustained xylitol release along time and, perhaps, this hypothesis could explain the present results. Significantly higher xylitol concentrations were released in saliva after application of the $20 \%$ xylitol varnish than of the $10 \%$ xylitol varnish on a short-term basis (up to $8 \mathrm{~h}$ ). Thereafter, this trend was inverted from 12 $h$ until the end of the experimental period (72 h). Therefore, the $10 \%$ xylitol varnish was able to produce sustained degrees of xylitol release along time. However, both varnishes were not removed from the dental surfaces throughout the time. This situation is not observed under clinical conditions, when dental varnishes are usually removed from tooth surfaces after 6 to $12 \mathrm{~h}$ from application. Taking this into account, a better clinical performance of the $20 \%$ xylitol varnish might be expected in relation to its $10 \%$ counterpart. Before any speculative conclusion, the performance of these varnishes needs to be tested in vivo regarding xylitol release and their caries-preventive effect.

\section{CONCLUSIONS}

Considering the limitations of this pioneer in vitro study, it can be concluded that sustained xylitol releases can be obtained in artificial saliva after application of $10 \%$ xylitol varnish, although $20 \%$ xylitol varnish released larger amounts of that polyol in the short-term. These varnishes seem to be viable alternatives to increase salivary xylitol levels and, therefore, they should be clinically tested to confirm their effectiveness.

\section{ACKNOWLEDGMENTS}

The authors are grateful to DANISCO Brasil Ltda (Cotia, SP, Brazil) for providing us with the xylitol and CAPES for financial support.

\section{REFERENCES}

1- Aaltonen AS, Suhonen JT, Tenovuo J, Inkilä-Saari I. Efficacy of a slow-release device containing fluoride, xylitol and sorbitol in preventing infant caries. Acta Odontol Scand. 2000;58(6):285-92. 2- Akerblom HK, Koivukangas T, Puukka R, Mononen M. The tolerance of increasing amounts of dietary xylitol in children. Int J Vitam Nutr Res Suppl. 1982;22:53-66

3- Autio-Gold J. The role of chlorhexidine in caries prevention. Oper Dent. 2008;33(6):710-6.
4- Bader JD, Shugars DA, Bonito AJ. A systematic review of selected caries prevention and management methods. Community Dent Oral Epidemiol. 2001;29(6):399-411.

5- Haresaku S, Hanioka T, Tsutsui A, Yamamoto M, Chou T, Gunjishima Y. Long-term effect of xylitol gum use on mutans streptococci in adults. Caries Res. 2007;41(3):198-203.

6- Hildebrandt GH, Sparks BS. Maintaining mutans streptococci suppression with xylitol chewing gum. J Am Dent Assoc. $2000 ; 131(7): 909-16$

7- Holgerson PL, Sjöström I, Stecksén-Blicks C, Twetman S. Dental plaque formation and salivary mutans streptococci in schoolchildren after use of xylitol-containing chewing gum. Int J Paediatr Dent. 2007;17(2):79-85.

8- Honkala E, Honkala S, Shyama M, Al-Mutawa S. Field trial on caries prevention with xylitol candies among disabled school students. Caries Res. 2006;40(6):508-13.

9- Hujoel PP, Mäkinen KK, Bennett CA, Isotupa KP, Isokangas PJ, Allen $P$, et al. The optimum time to initiate habitual xylitol gumchewing for obtaining long-term caries prevention. J Dent Res. $1999 ; 78(3): 797-803$.

10- Isokangas $P$, Söderling E, Pienihäkkinen K, Alanen P. Occurrence of dental decay in children after maternal consumption of xylitol chewing gum, a follow-up from 0 to 5 years of age. J Dent Res. 2000;79(11):1885-9.

11- Isotupa KP, Gunn S, Chen CY, Lopatin D, Mäkinen K. Effect of polyol gums on dental plaque in orthodontic patients. Am J Orthod Dentofacial Orthop. 1995;107(5):497-504.

12- Kandelman D, Gagnon G. A 24-month clinical study of the incidence and progression of dental caries in relation to consumption of chewing gum containing xylitol in school preventive programs. J Dent Res. 1990;69(11):1771-5.

13- Kato MT, Moraes Italiani F, Araujo JJ, Garcia MD, Carvalho Sales-Peres SH, Buzalaf MA. Preventive effect of an iron varnish on bovine enamel erosion in vitro. J Dent. 2009;37(3):233-6.

14- Kovari H, Pienihäkkinen $K$, Alanen P. Use of xylitol chewing gum in daycare centers: a follow-up study in Savonlinna, Finland. Acta Odontol Scand. 2003;61(6):367-70.

15- Lif Holgerson P, Stecksén-Blicks C, Sjöström I, Oberg M, Twetman S. Xylitol concentration in saliva and dental plaque after use of various xylitol-containing products. Caries Res. 2006;40(5):393-7.

16- Lif Holgerson P, Stecksén-Blicks C, Sjöström I, Twetman S. Effect of xylitol-containing chewing gums on interdental plaque-pH in habitual xylitol consumers. Acta Odontol Scand. 2005;63(4):233-8.

17- Ly KA, Milgrom P, Roberts M, Yamaguchi D, Rothen M, Mueller G. Linear response of mutans streptococci to increasing frequency of xylitol chewing gum use: a randomized controlled trial [ISRCTN43479664]. BMC Oral Health. 2006;6:6.

18- Ly KA, Riedy CA, Milgrom P, Rothen M, Roberts MC, Zhou L. Xylitol gummy bear snacks: a school-based randomized clinical trial. BMC Oral Health. 2008;8:20.

19- Magalhães AC, Kato MT, Rios D, Wiegand A, Attin T, Buzalaf MA. The effect of an experimental $4 \% \mathrm{Tif}_{4}$ varnish compared to $\mathrm{NaF}$ varnishes and $4 \% \mathrm{TiF}_{4}$ solution on dental erosion in vitro. Caries Res. 2008;42(4):269-74.

20- Mäkinen KK, Bennett CA, Hujoel PP, Isokangas PJ, Isotupa KP, Pape $\mathrm{HJ} J$ Jr, et al. Xylitol chewing gums and caries rates: a 40-month cohort study. J Dent Res. 1995;74(12):1904-13.

21- Mäkinen KK, Isotupa KP, Kivilompolo T, Mäkinen PL, Toivanen J, Söderling E. Comparison of erythritol and xylitol saliva stimulants in the control of dental plaque and mutans streptococci. Caries Res. 2001;35(2):129-35.

22- Marinho VC, Higgins JP, Logan S, Sheiham A. Topical fluoride (toothpastes, mouthrinses, gels or varnishes) for preventing dental caries in children and adolescents. Cochrane Database Syst Rev. 2003(4): CD002782.

23- Mickenautsch S, Leal SC, Yengopal V, Bezerra AC, Cruvinel V. Sugar-free chewing gum and dental caries: a systematic review. J Appl Oral Sci. 2007;15(2):83-8. 
24- Milgrom P, Ly KA, Roberts MC, Rothen M, Mueller G, Yamaguchi DK. Mutans streptococci dose response to xylitol chewing gum. J Dent Res. 2006;85(2):177-81.

25- Milgrom P, Ly KA, Rothen M. Xylitol and its vehicles for public health needs. Adv Dent Res. 2009;21(1):44-7.

26- Milgrom P, Ly KA, Tut OK, Mancl L, Roberts MC, Briand K, et al. Xylitol pediatric topical oral syrup to prevent dental caries: a double-blind randomized clinical trial of efficacy. Arch Pediatr Adolesc Med. 2009;163(7):601-7.

27- Söderling EM. Xylitol, mutans streptococci, and dental plaque. Adv Dent Res. 2009;21(1):74-8.
28- Söderling EM, Ekman T, Taipale T. Growth inhibition of Streptococcus mutans with low xylitol concentrations. Curr Microbiol. 2008;56(4):382-5.

29- Thneibat A, Fontana M, Cochran MA, Gonzalez-Cabezas C, Moore BK, Matis BA, et al. Anticariogenic and antibacterial properties of a copper varnish using an in vitro microbial caries model. Oper Dent. 2008;33(2):142-8.

30- Vieira AE, Delbem AC, Sassaki KT, Rodrigues E, Cury JA, Cunha RF. Fluoride dose response in $\mathrm{pH}$-cycling models using bovine enamel. Caries Res. 2005;39(6):514-20. 